\title{
Systems biology analysis of immune signaling in peripheral blood mononuclear cells (PBMC) of melanoma patients receiving ipilimumab; basis for response biomarker identification
}

\author{
Drew Hotson ${ }^{1 * \dagger}$, Ryan Alvarado ${ }^{1}$, Andy Conroy ${ }^{1}$, Santosh Putta ${ }^{1}$, Ester Simeone ${ }^{2}$, Assunta Esposito ${ }^{2}$, \\ Mariaelena Capone², Gabriele Madonna², Antonio M Grimaldi², David B Rosen', Spencer Liang1', \\ Alessandra Cesano ${ }^{1}$, Carmela Cacciapuoti ${ }^{2}$, Paolo A Ascierto², Rachael E Hawtin ${ }^{1+}$
}

From Melanoma Bridge meeting 2013

Naples, Italy. 5-8 December 2013

\section{Background}

Ipilimumab, an anti-CTLA-4 monoclonal antibody, is approved for treatment of unresectable/metastatic melanoma[1]. Treatment benefits only a subset of patients (pts) and is associated with significant adverse effects. Biomarkers of pt response are needed. Single cell network profiling (SCNP) is a multiparametric flow cytometry-based assay that quantitatively measures both phenotypic markers and changes in intracellular signaling proteins in response to modulation, enabling analysis of cell signaling networks[2,3]. We have been concerned on functional proteomic profiling of immune signaling pathways in PBMC subsets in healthy donors and pts with metastatic melanoma receiving ipilumumab treatment.

\section{Methods}

3 healthy and 13 melanoma pt cryopreserved samples, (7 pre-treatment (pre-Tx), 6 post-treatment (post-Tx)) were analyzed. Cells were assessed for viability, cell subset frequencies and signaling in response to modulation. A node is the combination of modulator and intracellular readout (e.g. IL-6 -> p-STAT3). Cytokine, TCR- or Fc $\gamma$ Rinduced activation of STAT1, 3, 5, CD3z and Erk was evaluated in immune cell populations and comparisons made based on disease, treatment time point and clinical responses.

\footnotetext{
* Correspondence: drew.hotson@nodality.com

† Contributed equally

${ }^{1}$ Nodality, Inc, South San Francisco, CA, USA

Full list of author information is available at the end of the article
}

\section{Results}

Compared to healthy, melanoma monocytes displayed lower IL-10 $\rightarrow$ p-STAT1, IL-10 $\rightarrow$ p-STAT3, IL-6 $\rightarrow$ p-STAT1, IL-6 $\rightarrow$ p-STAT3 and Fc $\gamma$ R $\rightarrow$ p-Erk. Similarly, $\mathrm{TCR} \rightarrow \mathrm{p}-\mathrm{CD} 3$ was reduced most prominently in CD45RA- CD4+ and CD4- T cells. These data suggest hyporesponsivity of circulating immune cell subsets in the innate and adaptive arms of the immune response in melanoma pts. The same observations pertained to melanoma samples independent from administration of, or clinical response to, treatment. Effects of treatment on T cell signaling were observed compared to healthy donors and pre-Tx samples. Post-Tx samples had diminished $\mathrm{TCR} \rightarrow \mathrm{p}-\mathrm{Erk}$, TCR $\rightarrow \mathrm{p}-\mathrm{CD} 3 \mathrm{z}$ in CD4+ and CD4- more prominently in CD45RA+ than CD45RA- subsets and diminished IL-15 $\rightarrow$ p-STAT5 in CD4- T cells. No markers associated with clinical response to ipilumumab. In samples from non-responsive pts, the level of basal p-Erk in CD45RA + CD4+ T cells and the percentage of Treg was higher compared to those of complete responders and healthy donors.

\section{Conclusions}

SCNP analysis of PBMC from healthy donors and melanoma pts pre-Tx and post-Tx identified signaling differences between melanoma and healthy and between pre- and post-Tx. Candidate predictive biomarkers for patient stratification will be evaluated in subsequent larger studies. 


\section{Authors' details}

${ }^{1}$ Nodality, Inc, South San Francisco, CA, USA. ${ }^{2}$ Istituto Nazionale Tumori,

Fondazione "G. Pascale", Naples, Italy.

\section{Published: 6 May 2014}

\section{References}

1. Hodi FS, O'Day SJ, McDermott DF, Weber RW, Sosman JA, Haanen JB, Gonzalez R, Robert C, Schadendorf D, Hassel JC, et al: Improved survival with ipilimumab in patients with metastatic melanoma. The New England journal of medicine 2010, 363:711-723.

2. Irish JM, Kotecha N, Nolan GP: Mapping normal and cancer cell signalling networks: towards single-cell proteomics. Nat Rev Cancer 2006, 6:146-155.

3. Cesano A, Putta S, Rosen DB, Cohen AC, Gayko U, Mathi K, Woronicz J, Hawtin RE, Cripe L, Sun Z, et al: Functional pathway analysis using SCNP of FLT3 receptor pathway deregulation in AML provides prognostic information independent from mutational status. PLOS ONE 2013, 8 . e56714.

doi:10.1186/1479-5876-12-S1-013

Cite this article as: Hotson et al: Systems biology analysis of immune signaling in peripheral blood mononuclear cells (PBMC) of melanoma patients receiving ipilimumab; basis for response biomarker identification. Journal of Translational Medicine 2014 12(Suppl 1):013.

\section{Submit your next manuscript to BioMed Central} and take full advantage of:

- Convenient online submission

- Thorough peer review

- No space constraints or color figure charges

- Immediate publication on acceptance

- Inclusion in PubMed, CAS, Scopus and Google Scholar

- Research which is freely available for redistribution

Submit your manuscript at www.biomedcentral.com/submit 